\title{
Variability of the Suspended Particle Cross-Sectional Area in the Bohai Sea and Yellow Sea
}

\author{
Qiong Tang ${ }^{1}$, Shengqiang Wang ${ }^{1,2}$, Zhongfeng Qiu ${ }^{1,2}, * \mathbb{D}$, Deyong Sun ${ }^{1,2}$ and \\ Muhammad Bilal ${ }^{1}$ (D) \\ 1 School of Marine Sciences, Nanjing University of Information Science \& Technology, Nanjing 210044, China; \\ 20171204312@nuist.edu.cn (Q.T.); shengqiang.wang@nuist.edu.cn (S.W.); sundeyong@nuist.edu.cn (D.S.); \\ muhammad.bilal@nuist.edu.cn (M.B.) \\ 2 Jiangsu Research Center for Ocean Survey Technology, NUIST, Nanjing 210044, China \\ * Correspondence: zhongfeng.qiu@nuist.edu.cn; Tel.: +86-25-5869-5692
}

Received: 1 April 2019; Accepted: 16 May 2019; Published: 18 May 2019

\begin{abstract}
A cross-sectional area (CSA) is a key element in the optical properties of suspended particles. The seasonal evolution of CSA has great potential for use in mapping total suspended particles, and such mapping plays an important role in water quality monitoring. In this study, the spatiotemporal variations in CSA in the Bohai Sea and the Yellow Sea were studied using temperature, salinity and chlorophyll-a data collected by four cruises. The CSA field data covered a wide range of spatiotemporal variabilities in the Bohai Sea and the Yellow Sea. The results revealed that the largest CSA $\left(>2 \mathrm{~m}^{-1}\right)$ was found in the coastal area, while the CSA $\left(\leq 1 \mathrm{~m}^{-1}\right)$ on the outer shelf was much smaller. Large values of CSA $\left(>15 \mathrm{~m}^{-1}\right)$ were observed in winter, whereas the smallest values of CSA $\left(0 \sim 2 \mathrm{~m}^{-1}\right)$ were observed in summer. These results suggest that vertical mixing and ocean stratification might be important physical mechanisms that influences the CSA seasonal distribution in the surface layer. The results also showed that phytoplankton played an important role in the CSA, with an $R^{2}$ value of 0.601 . The seasonal patterns of CSA documented in this study provide a fundamental theory for research on optical properties, mapping transparency, and photosynthetically active radiation.
\end{abstract}

Keywords: particle cross-sectional area; the Bohai Sea and Yellow Sea; spatiotemporal variations

\section{Introduction}

Suspended particles are one of the important components in coastal and oceanic water, and play an important role in the processes of biology, physics, and chemistry [1]. More specifically, the depth of light penetration is dependent on suspended particles due to the attenuation caused by absorption and scattering; thus, the penetration of light into the surface ocean is of great importance for productivity [2]. Meanwhile, the suspended particles in the surface layer are of extreme importance to solar radiation reaching the sea surface; hence, solar irradiance affects the sea surface temperature by controlling the energy budget in the surface ocean and further influences the depth of mixed layer and ocean stratification [3]. In addition, the backscattered light from suspended particles is an integral foundation of ocean color in monitoring suspended particles, water transparency, and turbidity [4-6]. Therefore, understanding the properties of suspended particles related to light absorption and scattering is essential for deepening the knowledge of water radiative transfer, aquatic photosynthesis processes, and ocean color algorithms.

Theoretically, the chance of a photon interacting with a suspended particle depends on the cross-sectional area (CSA) of the particle [7]. According to the Mie theory and the spherical hypothesis, for particles larger than a few wavelengths of light, the scattering and absorption coefficients become 
approximately proportional to the diameter of the particle [8]. Taking the backscattering coefficient $b_{\mathrm{bp}}(\lambda)$ as an example, based on the assumption of a sphere for the particle, the relationship between $b_{\mathrm{bp}}(\lambda)$ and diameter is expressed as follows $[9,10]$ :

$$
b_{b p}=Q_{b b e}(\lambda) \cdot \pi D^{2} / 4=Q_{b b e}(\lambda) \cdot \operatorname{CS} A(\lambda)
$$

where $Q_{\text {bbe }}(\lambda)$ and $C S A(\lambda)$ denote the backscattering efficiency and the cross-section area of the particle, respectively. Equation (1) shows that the CSA has a direct influence on the backscattering coefficient $\left(b_{\mathrm{bp}}\right)$, and this can also be analogized and applied to other optical properties, such as absorption, scattering, and light extinction coefficient, which is consistent with other laboratory and field studies $[7,11,12]$. Understanding the variability of the inherent optical properties is of great importance for the aquatic environment and remote-sensing applications [10]. Taking $b_{\mathrm{bp}}$ as an example, $b_{\mathrm{bp}}$ strongly influences the remote-sensing retrieval accuracy of total suspended matters (TSM) and chlorophyll-a concentration (Chl-a) [13]. Therefore, as previous studies have reported, the CSA possesses great importance to the research of optical properties $[7,14,15]$.

In recent decades, measuring the CSA of suspended matter in situ has become much easier through floc cameras and laser diffraction $[9,16,17]$. The distribution of particle volume concentration (VC) with size can be derived based on the Mie theory and the near-forward scattering measured by the LISST [16]. Supposing that the suspended particles are spherical and have material homogeneity, the CSA can be calculated based on the particle volume. Recently, there has been mounting evidence on the impact of CSA on optical properties $[7,9,11,12,14,15]$. Based on a series of complex experiments in the laboratory, Hatcher clarified that with the suspended flocs maturing, $b_{\mathrm{bp}}$ at six optical wavelengths $(442,470,510$, $589,620,671 \mathrm{~nm}$ ) were a function of CSA [12]. Mikkelsen et al. analyzed the relationship among CSA, VC, TSM, and the beam attenuation coefficient by using linear regression analysis, and found that the beam attenuation coefficient is directly affected by CSA [11]. Flory illustrated that a flocculation event may change the particle size distribution and further had an impact on the optical properties of the water column [9]. Tighter linear relationships among CSA, $b_{\mathrm{bp}}$, and the beam attenuation coefficient were found in the Bohai Sea and Yellow Sea [14]. Bowers found mounting evidence that remote sensing reflectance $\left(R_{\mathrm{rs}}(\lambda)\right)$ at the sea surface is more closely related to the CSA of suspended particles than to their mass [7]. Based on the close relationship between $R_{\mathrm{rs}}(\lambda)$ and CSA, Wang developed a remote sensing algorithm for CSA using the $R_{\mathrm{rs}}(\lambda)$ at 490 and $555 \mathrm{~nm}$ based on the Geostationary Ocean Color Imager (GOCI), with values of $R^{2}$, the root mean squared error (RMSE), and the mean absolute percentage error (MAPE) at $0.700,2.126 \mathrm{~m}^{-1}$, and $40.7 \%$, respectively [15]. Though the estimation of CSA is important, limited studies on the spatiotemporal distributions are available.

In view of the complexity and variability in the optical properties in the coastal ocean, the composition and concentration of particles may vary greatly, which will have an influence on the CSA $[9,12]$. The distribution and changes of CSA are beneficial for deepening the knowledge of research on the properties of suspended particle and ocean color. Hence, the aim of this study is to explore the CSA distribution and its impact mechanisms in the coastal ocean. The Bohai Sea and the Yellow Sea are typical shallow, semi-enclosed seas [18]. The warm and cold water masses in the Bohai Sea and Yellow Sea contain seasonal changes [19] that will have an effect on stratification in the ocean and lead to particle resuspension [20]. Additionally, the Yellow River and the Yangtze River have the second and the fourth largest sediment loads in the world, respectively, and transport approximately $1.08 \times 10^{9} \mathrm{t}$ and $4.78 \times 10^{8} \mathrm{t}$ sediment to their adjacent seas annually, respectively [20]. At the same time, as the semi-enclosed inland sea in China, the self-purification abilities in the Bohai and the Yellow Sea are very limited. In general, the Bohai and the Yellow Sea are home to dynamic and complex physical and biogeochemical oceanography through the influence of the river discharge and upwelling, as well as sediment resuspension. The relationship between the optical properties and CSA in the Bohai and the Yellow Seas has been studied [15], but there is no research on the controlling factors of the temporal and spatial distributions in CSA. 
Therefore, this study uses spring, summer, autumn, and winter observational data to explore the seasonal variability in the CSA distribution in the Bohai Sea and the Yellow Sea. Our aim is to give a more thorough picture of the seasonal CSA variation and to better understand the influence mechanisms underlying the CSA distribution in the Bohai Sea and the Yellow Sea using the observed salinity, temperature, wind, and chlorophyll data. Additionally, the study of the distribution of CSA can make the analysis of the suspended particles more robust and establish a theoretical foundation for studying the optical properties in coastal oceans.

\section{Materials and Methods}

\subsection{Study Area}

Four interdisciplinary oceanographic research cruises were used to collect data in the Bohai Sea and the Yellow Sea in November 2013, May 2014, and June and December 2016 (Figure 1), which separately represented the information in all four seasons. Each cruise took 16-20 days, and there were no episodic weather processes (for instance, typhoons and storm tides) during the cruises. The Bohai Sea and the Yellow Sea are typically shallow, semi-enclosed seas with case 2 waters [21]. The Bohai Sea is the largest inner sea of China $\left(117^{\circ} 30^{\prime}-121^{\circ} \mathrm{E}, 37-41^{\circ} \mathrm{N}\right)$, and it is a shallow sea with a total area of $77,000 \mathrm{~km}^{2}$ and an average depth of $18 \mathrm{~m}$ [22]. It can be divided into four parts with typical features: the Liaodong Bay (LDB), the Bohai Bay (BB), the Laizhou Bay (LB), and the Central Bohai Sea (CB) [22]. The Yellow Sea covers an area of approximately $380,000 \mathrm{~km}^{2}$ with average and maximum depths of approximately 44 and $140 \mathrm{~m}$, respectively [18]. In recent decades, due to the rapid development of agriculture and industry, abundant nutrients and sediments were exported to the Bohai and Yellow Sea [23], and together with the accumulative effects of winds, currents, and the resuspension of particles caused by vertical mixing, led to a low transparency and complicated optical properties for the water column [24].

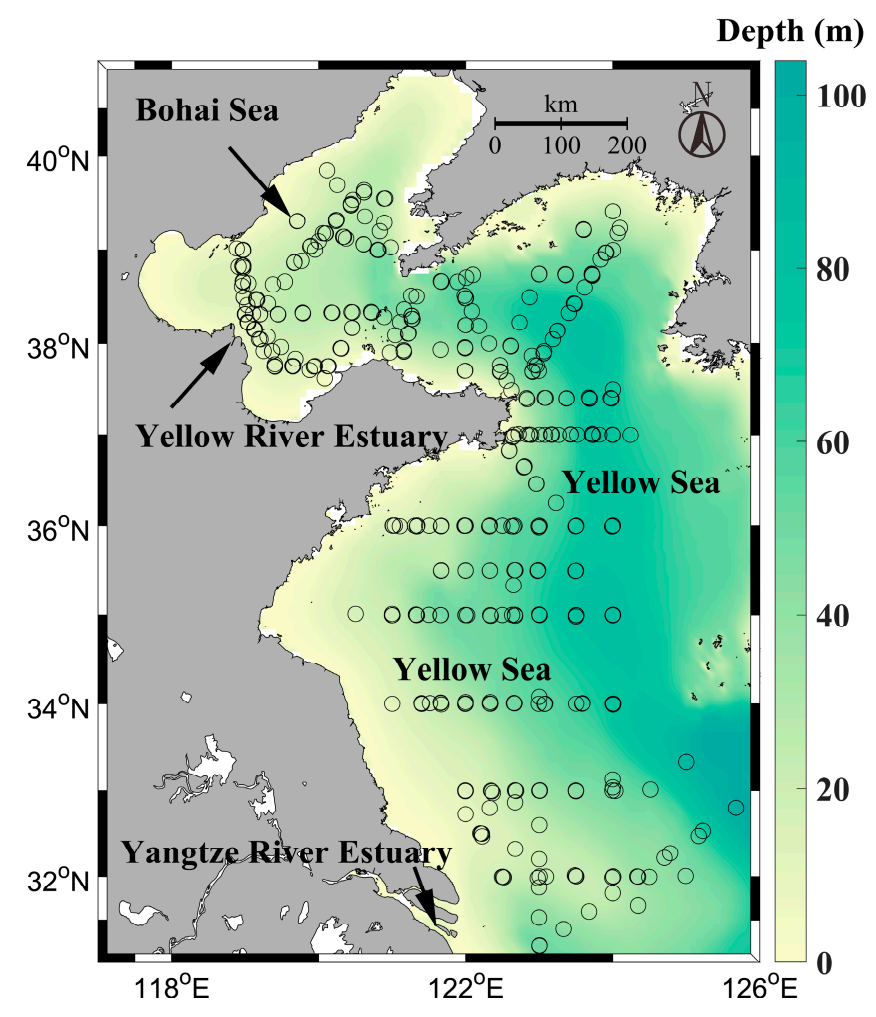

Figure 1. Locations of sampling stations in the Bohai Sea and the Yellow Sea during four cruises in 2013, 2014, and 2016. The colors indicate bathymetry. The thickened black line represents the selected section, which is expressed as section A, B, and C, respectively, from north to south. 


\subsection{In Situ Data Measurements}

The CSA concentration values were calculated from the field measurements of the volume scattering function via a LISST-100X Type-C particle size analyzer. The background scattering measurement of LISST is critical to optimal instrument performance and for checking the overall health of the instrument. Hence, to examine the stability of this instrument, the LISST was calibrated with Milli-Q ultrapure water before each cruise survey [18]. If there was a problem with the instrument or if the water or windows were not clean, error messages would be displayed. At each station, the LISST instrument was put into the water, and then, pulled close to the surface after 3-5 minutes and deployed downward again until the sea bottom was reached. To prevent perturbations affecting the water column, only downcast measurements were valid for data analysis [15]. The LISST instrument had 32 size ranges logarithmically distributed across a continuous size spectrum from 2.5 to $500 \mu \mathrm{m}[7,25,26]$. The upper size of each bin was 1.18 times larger than the lower bin, and the width of the size classes varied from 0.45 to $76 \mu \mathrm{m}$ [19]. Scattered light in the near forward-scattering angles was measured on detector rings, and the inversion model was established based on the Mie theory to calculate the particle volume concentration in the 32 size bins [17]. According to the measured volume concentration of suspended particles, the cross-sectional area concentration values were estimated effectively. With the hypothesis that particles are a standard sphere, the cross-sectional area concentration can be obtained as follows [7,15]:

$$
C S A_{i}=\frac{3}{2 D_{i}} V C_{i}
$$

where $C S A_{\mathrm{i}}, D_{\mathrm{i}}$, and $V C_{\mathrm{i}}$ denote the cross-sectional area concentration, mean diameter, and volume concentration of the particles in size bin $i$, respectively. As noted by previous studies [27-29], the measurement of LISST usually shows significant instability in the minimum and maximum size range, which may be caused by the existence of suspended particles smaller than or larger than the size used. Therefore, we excluded the minimum and maximum size data from our analysis. Then, we summed all the cross-sectional area concentration whose sizes binned from 2 to 31 and obtained the total cross-section area concentration:

$$
C S A=\sum_{i=2}^{31} C S A_{i}
$$

where $i$ ranges from 2 to 31 with corresponding values of $3.2 \mu \mathrm{m} \leq D_{\mathrm{i}} \leq 390 \mu \mathrm{m}$.

At each station, a Conductivity-Temperature-Depth (CTD) system was put into the water during the summer and winter cruises. When the CTD was deployed vertically from the sea surface to the bottom during the cruises, a minimum distance (approximately 3-5 $\mathrm{m}$ ) between the CTD and the seafloor was maintained to protect the instrument. Therefore, only temperature and salinity near the bottom were measured by the CTD.

Each water sample (1000-4000 $\mathrm{ml}$ determined by water turbidity) was filtered with a $47 \mathrm{~mm}$ Whatman GF/F filter. The filters were dried at a constant temperature of $105^{\circ} \mathrm{C}$ for $3 \mathrm{~h}$ to obtain TSM with an accuracy of $0.01 \mathrm{mg}$. Then, the filters were pre-combusted at a constant temperature of $450{ }^{\circ} \mathrm{C}$ for $5 \mathrm{~h}$ to remove organic matter and obtain the inorganic suspended matter (ISM) with an accuracy of $0.01 \mathrm{mg}$. The organic suspended matter (OSM) is obtained by subtracting ISM from TSM.

Water samples were collected $(100 \mathrm{ml})$, then filtered onto $25 \mathrm{~mm}$ filters $(\mathrm{GF} / \mathrm{F}$, Whatman) under a low suction pressure $(<0.1 \mathrm{kPa})$. The filters were immediately frozen in liquid nitrogen for subsequent laboratory analysis. The Chl-a pigments were extracted from the filters by $\mathrm{N}$, $\mathrm{N}$-dimethylformamide, and the Chl-a concentrations were determined fluorometrically using the Turner Design (Trilogy) fluorometer.

Statistical analysis was performed with MATLAB software (MathWorks Inc., Natick, MA, USA). In this study, a standard statistical measure known as the coefficient of determination $\left(R^{2}\right)$ was used to gauge the relationship between the CSA and Chl-a [15]. 


\section{Results}

\subsection{Hydrography}

Based on the CTD data measured during the summer and winter cruises, the hydrological characteristics of the Bohai and the Yellow Sea were analyzed (Figures 2 and 3). The ocean stratification and vertical mixing were suitable proxies for characterizing the water column $[9,30]$. According to the definition of the mixed layer depth (MLD) and the thermocline, in this paper, the difference values of temperature, salinity, and density between the surface and bottom were used to indicate the strength of vertical turbulence mixing. More specifically, the smaller temperature difference between the surface and bottom indicated a weaker stratification stability, which was opposite to the salinity. The greater top-to-bottom salinity difference corresponded to strong vertical mixing [31]. The spatial distributions of the differences between the surface and bottom hydrological features (the difference between the surface and bottom) are shown in Figure 2. In summer, the minimum temperature difference was mostly located in the Bohai Sea (Figure 2a), especially the Yellow River Estuary, which means that the stratification was weak. Near the Shangdong Peninsula and Subei Shoal, there were slightly larger value zones, as the water column was mixed thoroughly by the shallow water. The difference $\left(\Delta \mathrm{T}>6^{\circ} \mathrm{C}\right)$ was large in the outer sea, thus implying that the stratification was stable. The salinity and density difference distribution were similar to the temperature difference distribution in summer, which indicated that the water column near the coastal was mixed more uniformly. There was a striking difference between summer and winter. Figure $2 \mathrm{~d}$ shows that the temperature difference was small on the whole, and had a maximum $\left(\Delta \mathrm{T}<0.5^{\circ} \mathrm{C}\right)$ in the center of the Yellow Sea; this meant that the winter ocean stratification was weaker than the summer in its entirety and the water column was mixed uniformly, especially near the shore. The salinity and density distributions also proved this point.
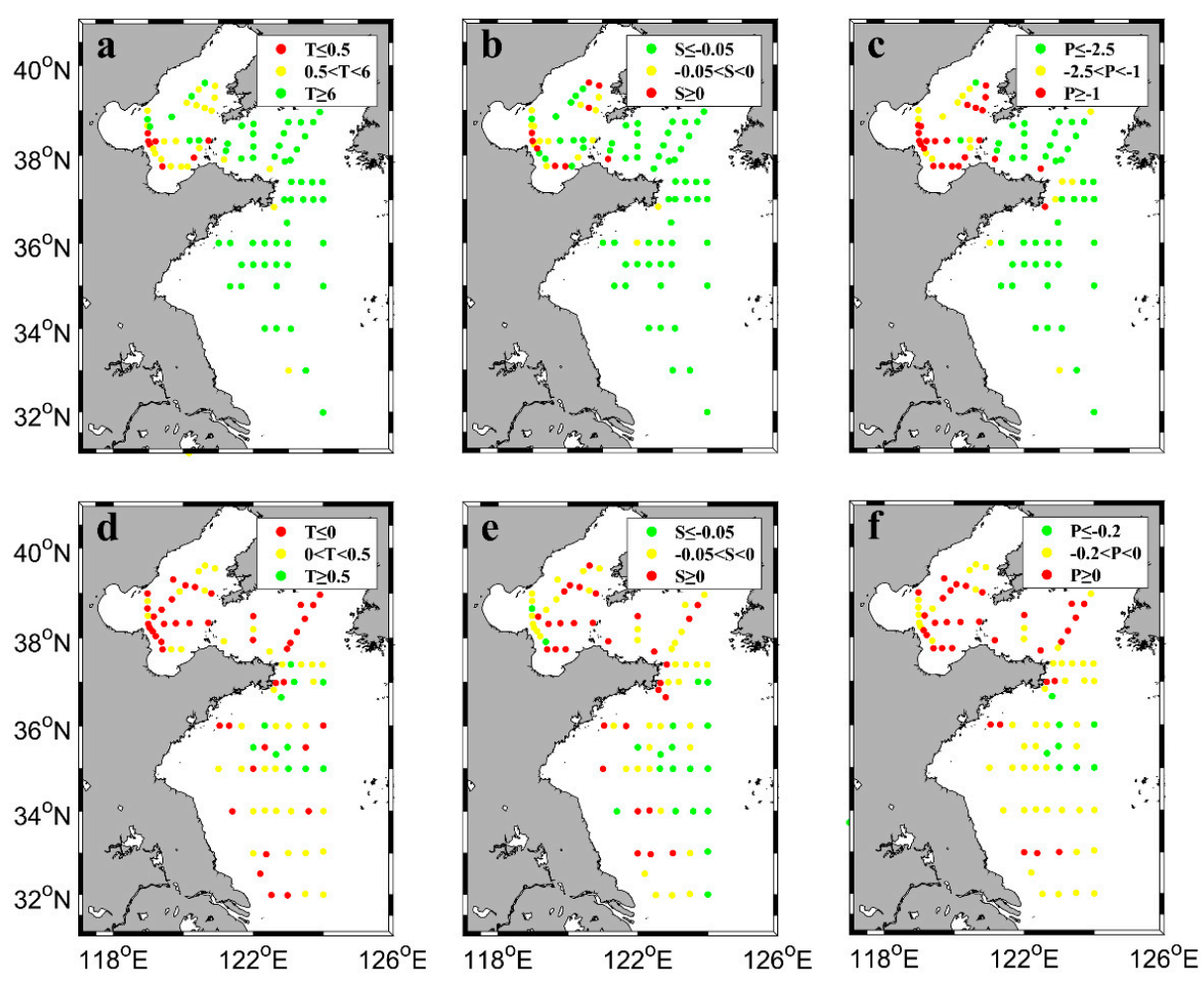

Figure 2. Spatial distributions of the normalized differences (difference values between the surface and bottom) of surface and bottom hydrological features, including the temperature $\left(\mathrm{T}\right.$, unit: $\left.{ }^{\circ} \mathrm{C}\right)$, the salinity (S, unit: psu), and the density ( $\mathrm{P}$, unit: $\mathrm{kg} / \mathrm{m} 3) ;(\mathbf{a}-\mathbf{c})$ show summer measurements, and (d-f) show winter measurements. 

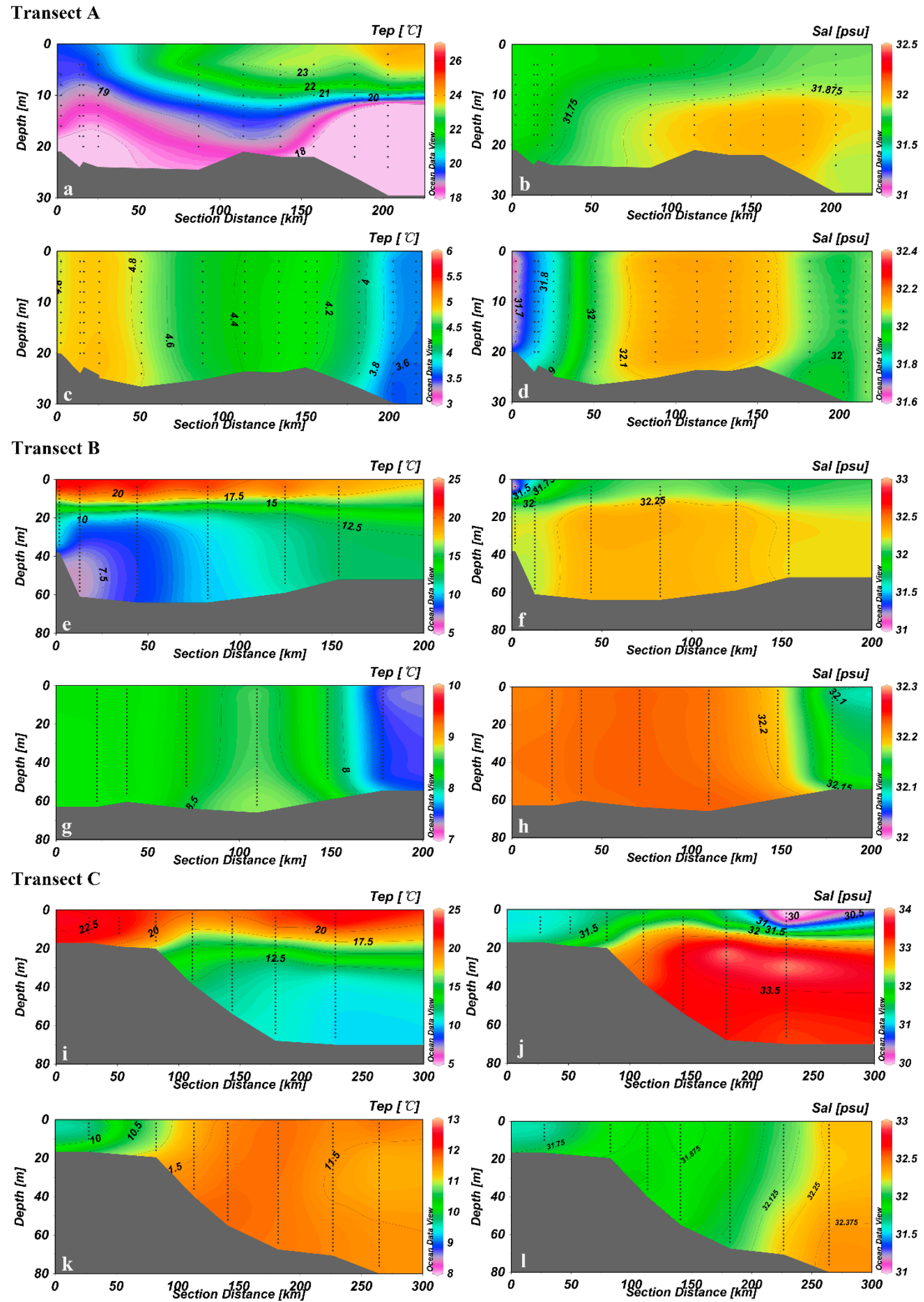

Figure 3. Distributions of temperature and salinity: (a-d) are transect $A,(\mathbf{a}, \mathbf{c})$ are the temperature in summer and winter, respectively; $(\mathbf{b}, \mathbf{d})$ are the salinity in summer and winter, respectively. $(\mathbf{e}-\mathbf{h})$ are transect $B$, the sequence is the same as that on transect $A ;(i-1)$ are transect $C$, the sequence is the same as that on transect $\mathrm{A}$. 
The distributions of temperature and salinity on transects $A, B$, and $C$ in summer and winter (Figure 3) were used to study the effects of temperature and salinity on the CSA vertical distribution in the Bohai and Yellow Sea. In summer, the vertical temperature difference of the three transects was obvious, and the sharp change of the temperature contour line at approximately 15-20 m implied the existence of thermocline (Figure 3a,e,i). In transect $C$, the water column was mixed more uniformly in shallow water, and the depth of the mixed layer reached up to $20 \mathrm{~m}$ (Figure 3i). The vertical salinity distribution was similar to the temperature, which had an obvious stratification (Figure $3 b, f, j)$ ). When the water column was stratified (the thermocline was formed), the vertical mixing near the surface was stronger, and the vertical mixing in the subsurface was weak. A striking difference between the vertical distribution of temperature and salinity in winter and summer was observed. In winter, the vertical temperature (Figure $3 c, g, k$ ) and salinity (Figure $3 d, h, l$ ) were uniform from the sea surface to the bottom, which indicated the water column was mixed thoroughly.

Since the CTD data in spring and autumn were not available, the hydrological features of the spring and autumn season are not displayed in this section. Previous studies argued that the vertical mixing degrees in spring and autumn were between those in summer and winter [32,33]. In more detail, as the sea surface temperature increases, the thermocline starts to form so that the mixed layer raises rapidly and the mixed layer depth becomes shallower in spring [32,33]. Conversely, as the sea surface temperature in autumn gradually decreases, the thermocline is broken down and the stratification stability becomes weaker so that the depth of the mixed layer continues deepening until reaching the maximum in winter. Therefore, the mixed layer depth in autumn is second to that in winter.

In short, strong vertical mixing is found in autumn and winter. The thermocline starts to form in spring and the vertical convection gradually diminishes. Since the stratification in summer is strongest among the four seasons, so then the vertical mixing is weakest [32,33].

\subsection{Horizontal Distribution of CSA}

The spatiotemporal CSA distributions in the surface layer of the Yellow Sea and the Bohai Sea observed during each cruise are displayed in Figure 4. Overall, the CSA of the four seasons nearshore was higher than offshore. The highest CSA was located in the Subei Shoal and was extended to the southeast part of the Yellow Sea. Meanwhile, the CSA distribution showed seasonal differences, and the seasonal variations in different regions were also different. For example, the most obvious seasonal variations were found offshore. The surface patterns of CSA showed that the offshore CSA in winter was largest, and its maximum value reached up to $1 \mathrm{~m}^{-1}$. The CSA in spring was second and the maximum zone was located at the center of the South Yellow Sea, and the CSA in summer near offshore was the smallest, at only approximately $0.5 \mathrm{~m}^{-1}$. Moreover, compared with the CSA offshore, the surface variation in CSA in the coastal areas was smaller, and the CSA in winter was larger, while the CSA in summer was the smallest. In spring, the large CSA value was located at Subei Shoal. During summer, the CSA nearshore was low, at only approximately $1.5 \mathrm{~m}^{-1}$. In autumn, the CSA was much larger than that in summer, and the CSA in the Bohai Sea increased obviously, especially near the Yellow River estuary areas. The CSA in winter was larger than other seasons in general, and the largest CSA $\left(\geq 15 \mathrm{~m}^{-1}\right)$ was located in the Subei Shoal and Yellow River estuary areas. Compared with the other three seasons, the CSA near the southwest part of the Korean peninsula also increased during winter. 

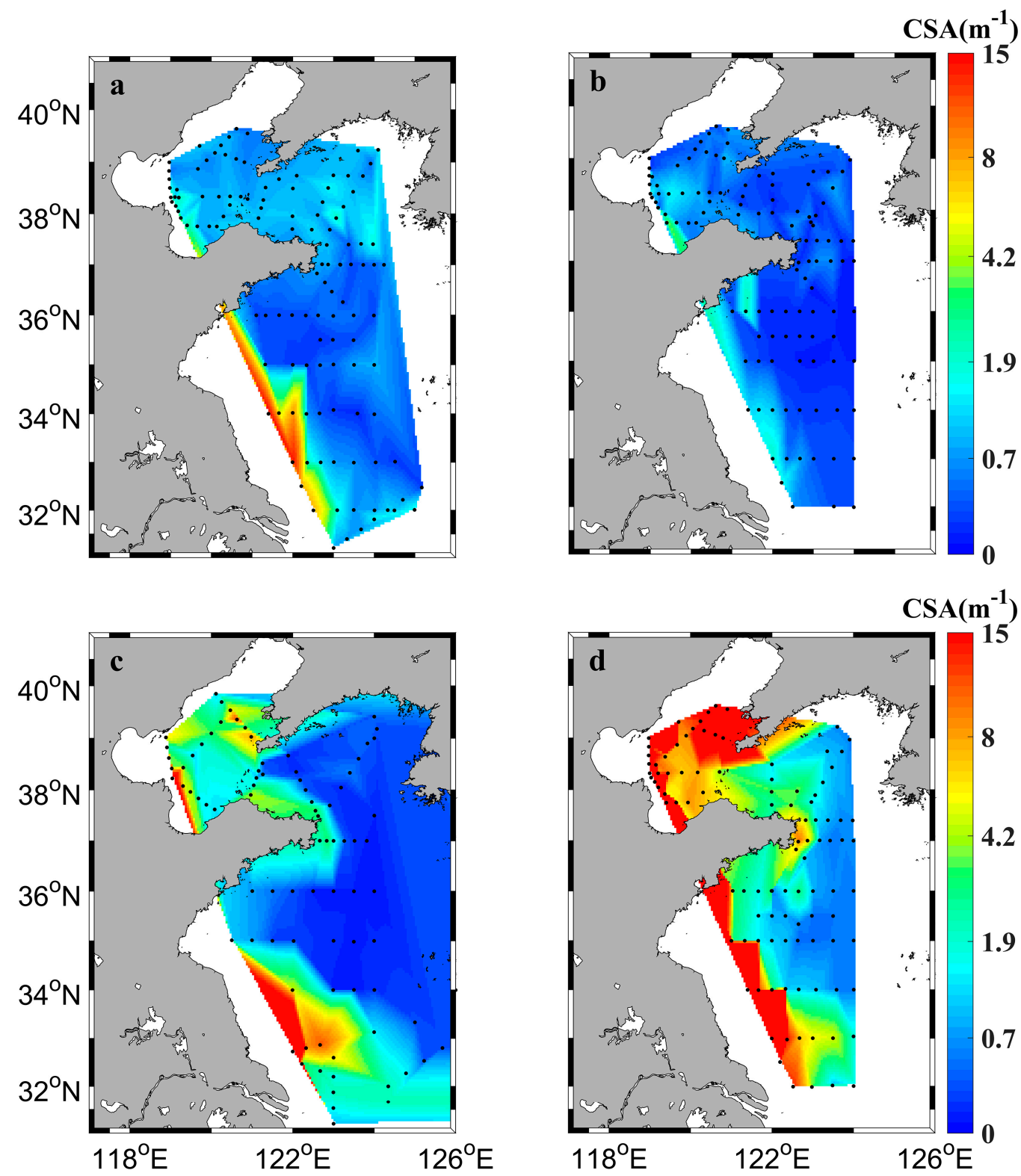

Figure 4. Cross-sectional area (CSA) distribution in the surface layer in (a) spring, (b) summer, (c) autumn, and (d) winter. The interpolation was implemented by the nearest-neighbor interpolation in Matlab (R2016a).

Based the CTD depth deployed from the sea surface to the seafloor, we selected the middle and bottom layer. The spatiotemporal distributions of CSA in the middle and bottom layer in the Bohai and the Yellow Seas are shown in Figures 5 and 6, respectively. The CSA in the middle distribution was similar to that on the surface. The nearshore CSA was larger than that of the offshore. As shown in Figure 5, there were also obvious seasonal variations in the CSA distribution in the middle layer. The CSA in winter and autumn were larger, and the CSA in summer was smallest. The CSA in spring was slightly larger than that in the summer. Overall, the values of CSA in the middle layer were larger than the CSA on the surface.

Compared with the surface and middle distribution of CSA, the CSA on the bottom increased evidently and was largest (Figure 6). Meanwhile, the seasonal variability of CSA on the bottom layer was the same as the surface and middle layers, in which the maximum CSA value was in winter and the CSA in summer was smallest. 

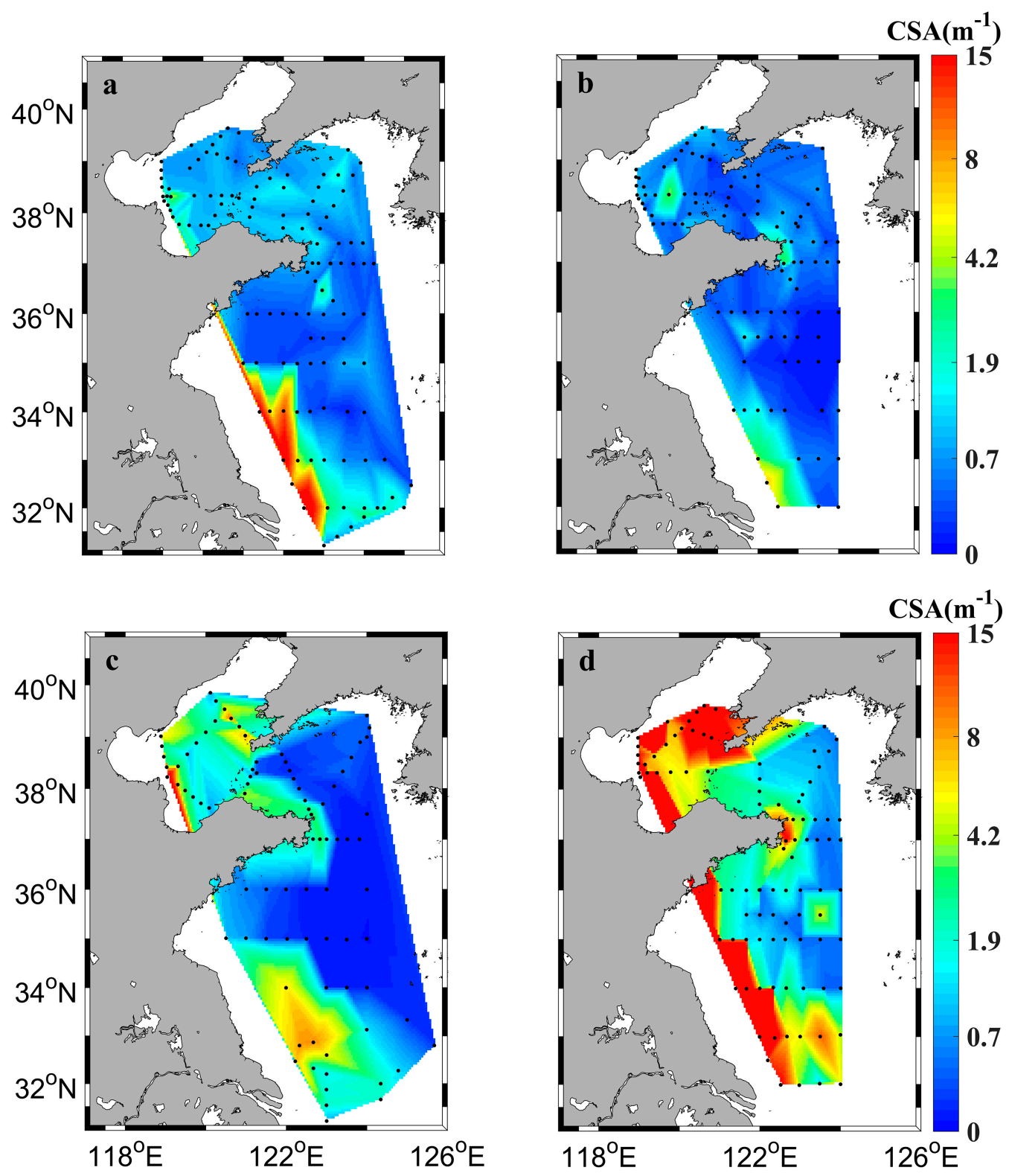

Figure 5. CSA distribution in the middle layer in (a) spring, (b) summer, (c) autumn, and (d) winter. The interpolation method was the same as Figure 4. 

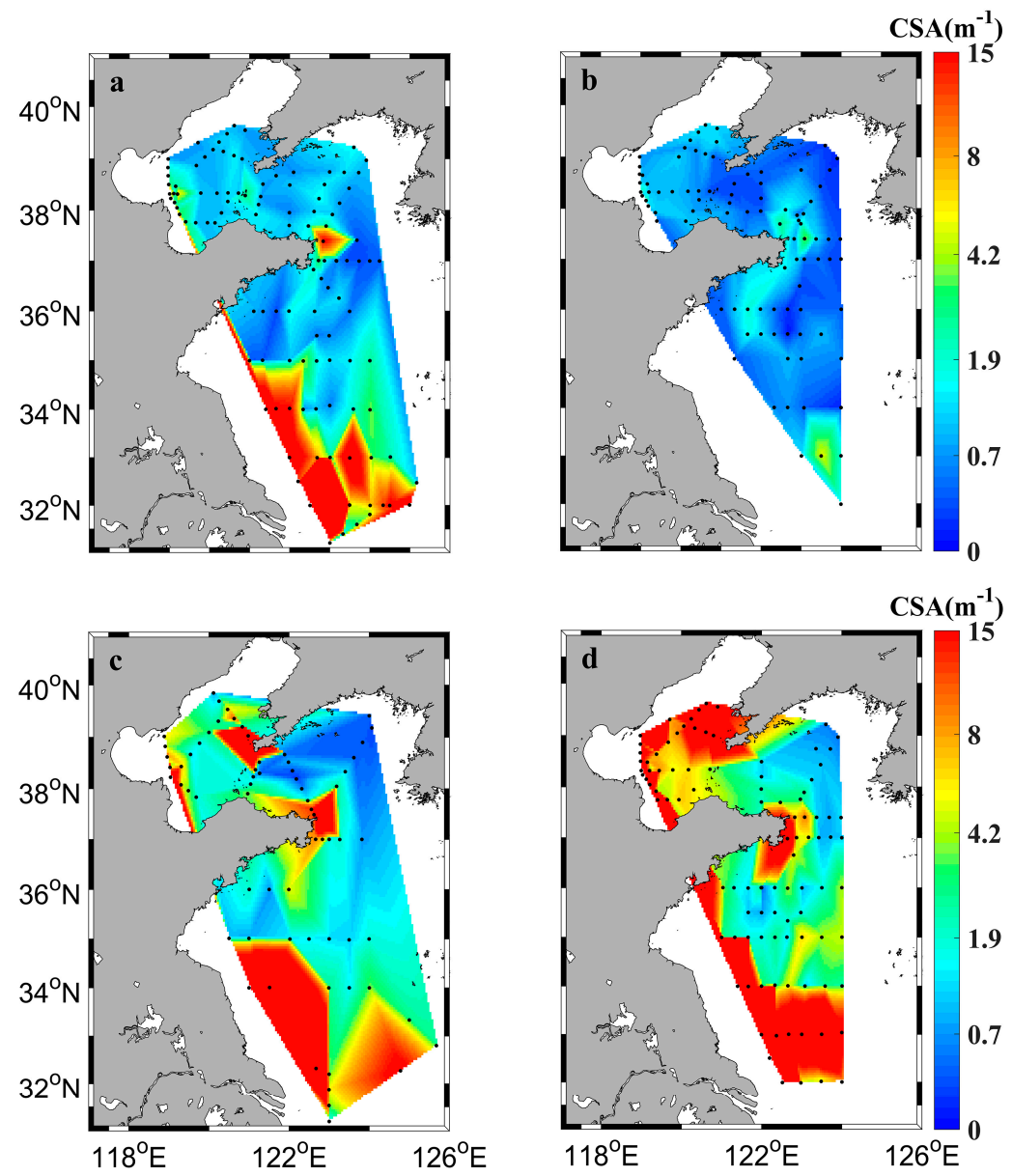

Figure 6. CSA distribution in the bottom layer in (a) spring, (b) summer, (c) autumn, and (d) winter. The interpolation method was the same as Figure 4.

\subsection{The Vertical Profiles of CSA}

To thoroughly investigate the relationship between CSA distribution and the change in water depth, we selected three transects during the four cruises based on the specificity of geographical location and the number of stations in each transect (Figure 1). Figure 7a-d illustrates the CSA vertical distribution in transect A $(0-220 \mathrm{~km})$ during spring, summer, autumn, and winter. Transect A (Figure 1) was located in the Bohai Sea, at the left side of the Yellow River Estuary and on the right side of Liaodong Bay. In general, the CSA values on both sides of the section were relatively large, and compared with the right side, the CSA near the Yellow River estuary was larger. With the increase of the distance from the shore, the CSA gradually decreased. However, the values of CSA increased with the depth which corresponded with the CSA distribution in the surface, middle, and bottom layers, except for the CSA near the coast in summer. Additionally, the vertical distribution of CSA had the same seasonal distribution with the horizontal distribution, which was that the CSA in summer was smallest and the CSA in winter was largest. Compared with the other seasons, the CSA in winter, especially near the Yellow River estuary, was obviously largest, with a maximum value of $28 \mathrm{~m}^{-1}$. In transect B (0-200 km), the CSA in the bottom (Figure 7e-h) was greater than on the surface. However, the CSA values in spring and summer were an exception. In spring, the CSA in the surface (Figure 7e) in the middle of the transect was slightly larger than the CSA in the subsurface layer. The CSA in summer (Figure 7f) showed a strong stratification and the maximum CSA was found in the subsurface. Transect C (0-300 km) (Figure 1) is a section of the Southern Yellow Sea, located near $34^{\circ} \mathrm{N}$. Although the CSA value in winter was largest, the trend of the CSA vertical distributions in spring, autumn, and 
winter were roughly approximate, while the CSA vertical distribution was uniform. The nearshore CSA was much greater than the offshore. The maximum zone of CSA was around the Subei Shoal and gradually extended offshore. In comparison with the other seasons, the CSA in summer showed a greater difference. In summer, the CSA in section C bore a resemblance to section B, which had a CSA stratification in the subsurface and the CSA maximum was found in the subsurface and bottom layer.

\section{Transect A}
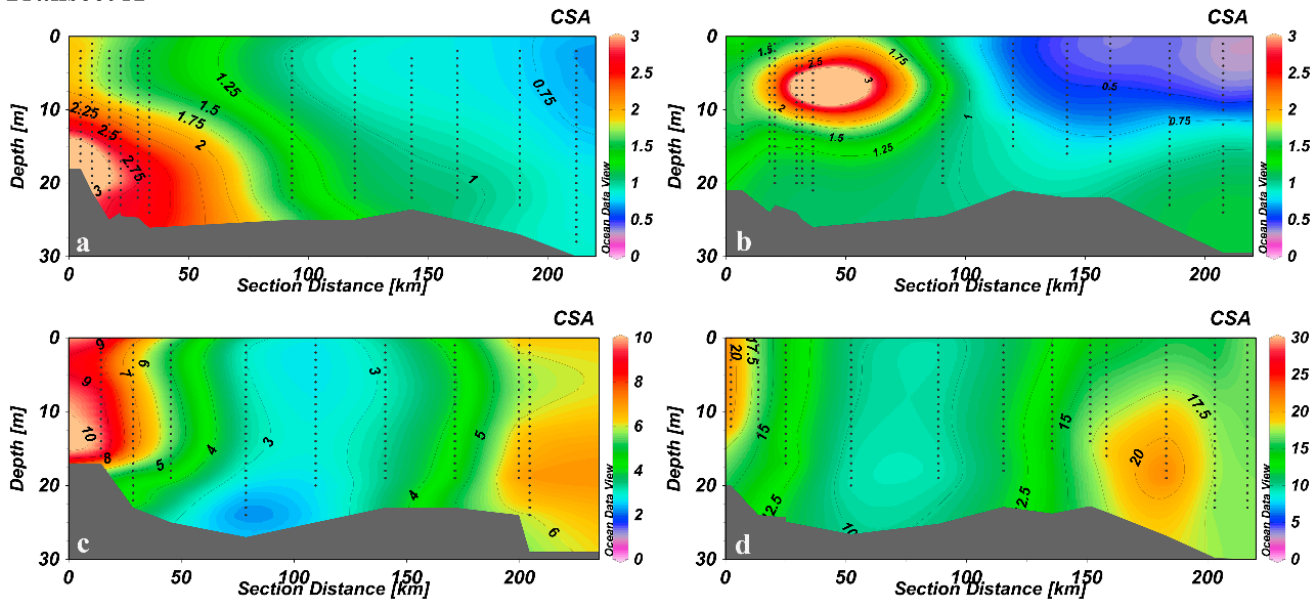

\section{Transect B}
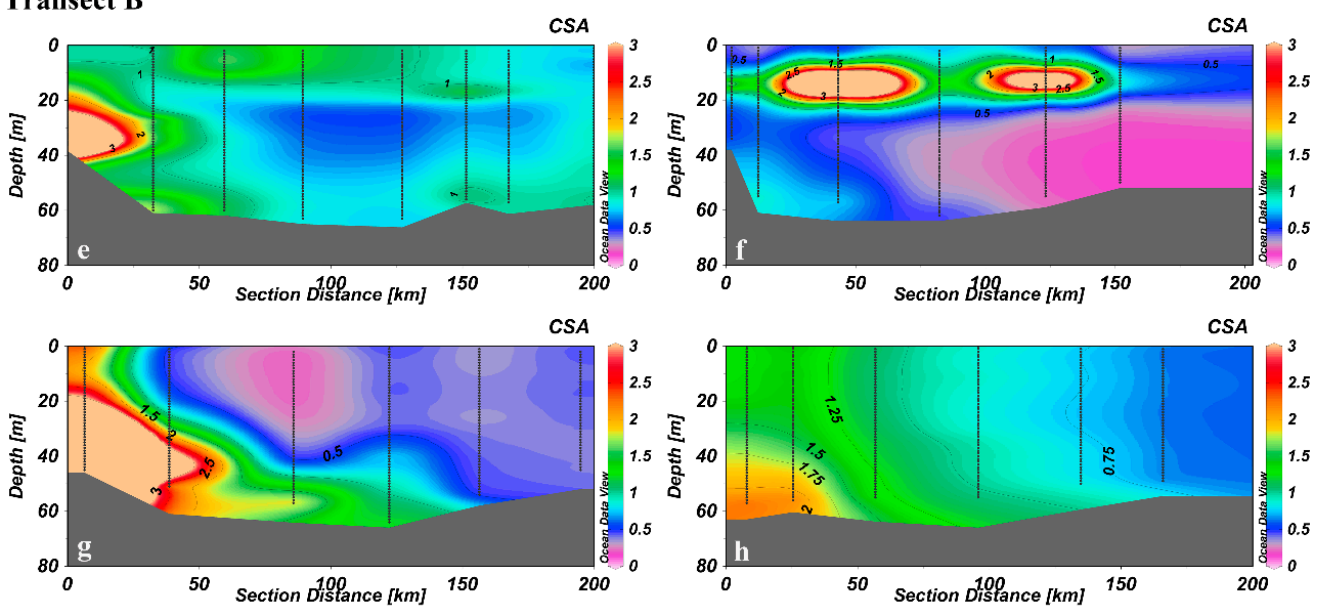

\section{Transect C}
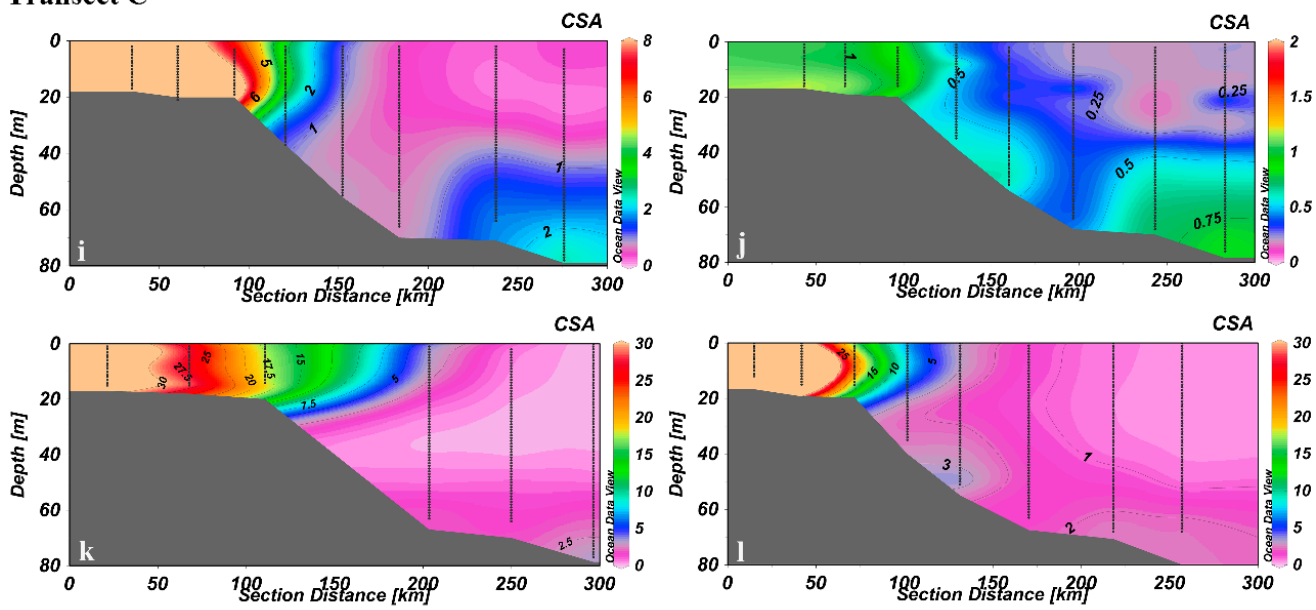

Figure 7. The CSA vertical profiles (unit: $\mathrm{m}^{-1}$ ) at each cruise: (a-d) are transect $\mathrm{A},(\mathbf{a}-\mathbf{d})$ are spring, summer, autumn, winter, respectively; $(\mathbf{e}-\mathbf{h})$ are transect $B$, the sequence is the same as that on transect $A ;(i-1)$ are transect $C$, the sequence is the same as that on transect $A$. The interpolation method is the same as Figure 3. 


\section{Discussion}

\subsection{Patterns of CSA Variation in the Bohai and Yellow Sea}

Previous studies have commonly investigated the importance of CSA on optical properties $[7,9,11,12,14,15]$. In order to deepen the knowledge of the influences of CSA variations on suspended particles and ocean color in coastal oceans, the spatiotemporal distributions of CSA and their influencing factors must be explored. The results (Figures 4-6) for the seasonal patterns of CSA in the Bohai and the Yellow Sea revealed that the CSA varied on both spatiotemporal scales. The CSA is shown to be dependent on TSM, VC, the particle size spectrum, and the mean effective density of suspended particles [11]. The particles can be divided into OSM and ISM, as presented in Figure 8. Therefore, to some extent, the CSA will increase and vary as a function of increasing the OSM and ISM, and the influences of composition of suspended particles on CSA will be discussed. A previous study argued that hydrodynamic forcing agents, such as the vertical turbulence mixing, tidal current, and subtidal current, will bring the sediment resuspension and transportation [20], which may play a significant role in determining the CSA distribution.
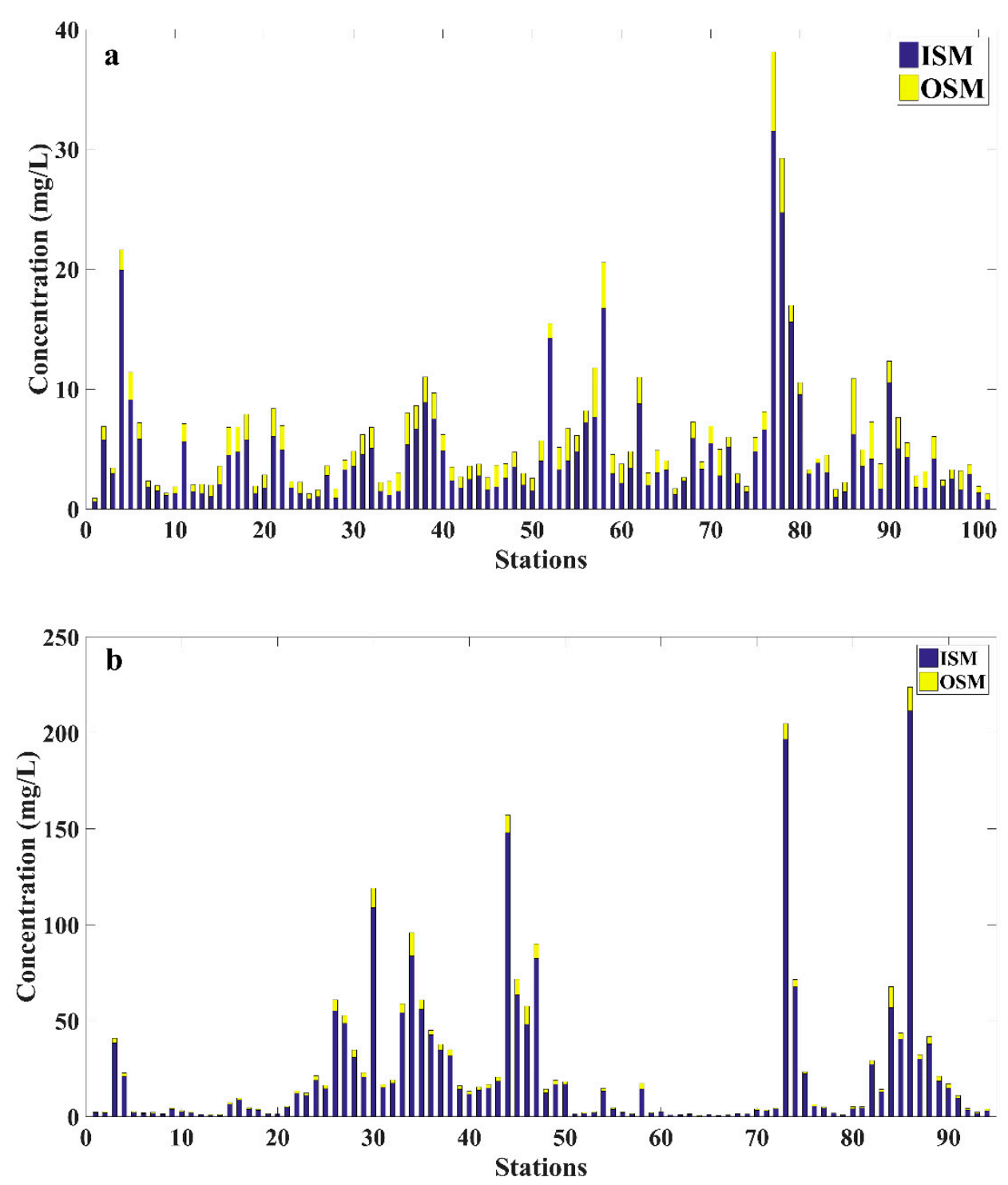

Figure 8. The organic suspended matter (OSM) and inorganic suspended matter (ISM) concentration in each station for (a) summer; (b) winter. 
The thermocline forms the layer that acts as a barrier to vertical mixing and then restricts sediment movement; the thermocline begins to form in spring and becomes strongest in summer [32,33]. At the same time, the summer wind speed was too weak to stir the water column [20] (Figure 9b), thus the vertical mixing was weakest in the four seasons (Figure $2 a, b$; Figure $3 a, b, e, f, i, j)$. Due to the form of the thermocline and weak vertical mixing (Figure $3 a, b, e, f, i, j)$, the seabed suspended matter could not be easily transported to the sea surface so that the CSA in the surface was smallest (Figure $4 \mathrm{~b}$ ). In the coastal ocean, given the shallow water, the water column was susceptible to perturbations induced by the wind. The stability of the stratification was weaker compared with offshore. Consequently, the maximum CSA in the surface layer was found in the near shore areas.
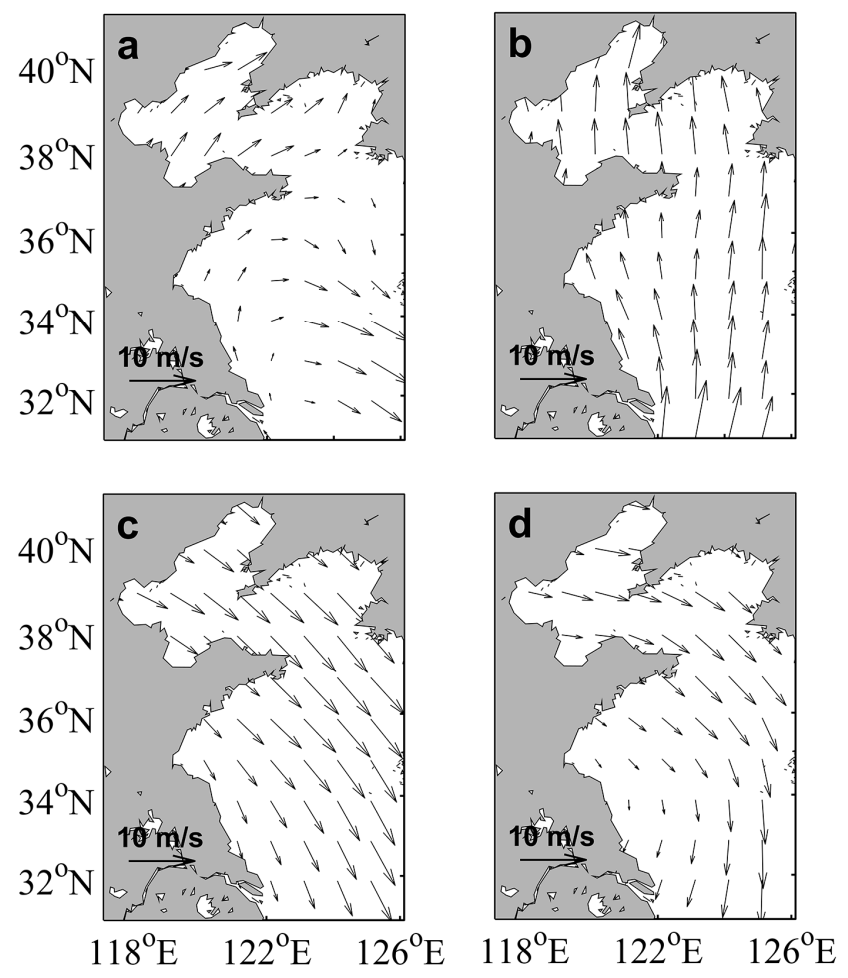

Figure 9. Mean wind velocity during four cruises for (a) spring; (b) summer; (c) autumn; (d) winter. The wind data was retrieved from http://www.remss.com/.

In winter, the stratification broke down and the vertical mixing became strongest due to the strong northerly monsoon wind and surface cooling. The curl of wind stress associated with the wind waves stirred the seabed sediment into the water column and brings about the particle suspension $[20,34,35]$. Furthermore, the sea surface temperature was lowest so that the surface cooling strengthened the vertical mixing $[36,37]$. Therefore, the water column was highly mixed leading to the sediment being transported to the surface, which caused the largest CSA in the surface layer (Figure 4d).

In spring, with the increase of heat input on the sea surface, the stratification was gradually stable because of the form of the thermocline [32,33], which restricted the bottom sediment movement. Furthermore, the wind speed was weak enough to retain vertical mixing (Figure 9a). Therefore, the CSA in the surface was small, specifically in the outer sea (Figure 4a).

During autumn, not only did the mean wind speed increase (Figure 9c) but the sea surface temperature also gradually decreased. Hence, the vertical mixing induced by strong wind and surface cooling enhanced. In the Bohai and the Yellow Seas, the thermocline began to form in April and disappeared in September [32,33]. Therefore, the highly mixed water column carried the bottom layer suspended sediment upwards to the sea surface easily. As a result, the CSA at sea surface increased and ranked only second to the CSA in winter. 
The resuspension of sediments induced by vertical mixing can increase the CSA on the sea surface, as mentioned above. Additionally, as the phytoplankton bloom began and progressed, the organic particles increased, and detrital particles gradually aggregated to form loose flocs [9,12], which increased the cross-section area of the suspended particles. Furthermore, the oceanic chlorophyll-a concentration (Chl-a) is the important indicator of phytoplankton [38]. Thus, to some extent, the Chl-a concentration may be used as the representative of the phytoplankton contribution to CSA. Due to the occurrence of phytoplankton bloom, the increasing organic particles concentration, together with the flocculation, led to an increase in CSA [9]. In summer, the strong stratification not only prevented the sediments in the bottom from being transported to the surface, but also was strong enough to inhibit the bottom layer nutrients from being entrained to the surface layer. Therefore, the available nutrients in the surface are gradually consumed, and the phytoplankton concentration decreased. However, the phytoplankton kept growing in the subsurface, and thus the appearance of subsurface chlorophyll maximum layer (SCML) was found in the stratified water column [39]. As a result, an obvious stratification of the CSA was discovered in the subsurface layer, as Figure 7b,f,j show. When winter came, the phytoplankton biomass decreased as a function of decreasing temperature. As a result, the contribution of organic particles to CSA was thoroughly decreased.

To more thoroughly explore the relationship between CSA and Chl-a, the correlation of CSA and Chl-a measured during summer and winter (the cruise data in spring and autumn were unavailable) is shown in Figure 10. In the surface layer, although the Chl-a concentration in summer was lower than in spring and autumn because of the phytoplankton bloom and the SCML (Figure 7f,j) induced by the strong stratification [39], the correlation in summer was slightly higher, at up to 0.601 (Figure 10a). The high CSA in few observations were represented by open symbols corresponding to the low Chl-a concentration, which was mostly because these stations were located near the coast, and due to the shallow water, the resuspended sediments were also present. In winter, compared with the correlation coefficient in summer, the correlation between the CSA and Chl-a was lower (Figure 10b), at only at $R^{2}$ $=0.145$. In summer, most CSA concentration increased as a function of the increasing Chl-a, but this did not happen in winter. The ISM in winter was far greater than OSM compared with summer (Figure 8), which implied that in winter, instead of the low phytoplankton concentration, the resuspension of sediments caused by wind and surface cooling was likely the main factor that dominated the CSA and needs to be studied further. Due to the lack of field Chl-a data in spring and autumn, currently, we can only give a general discussion on the influence of phytoplankton on CSA. Further investigations focusing on this topic are still required in future.
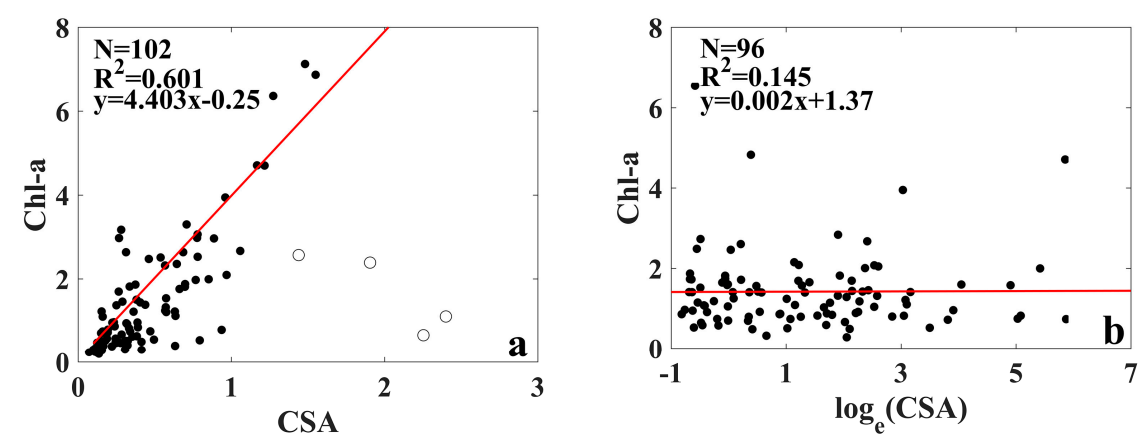

Figure 10. The relationship between CSA and chlorophyll-a concentration (Chl-a) for (a) summer; (b) winter; the red lines represent the fitting curve. The open circles represent sampling stations located near the coast.

Except for the two factors previously mentioned, the suspended particles transported by runoff may also increase the CSA near the offshore area. The Yellow River and the Yangtze River, which have the second and the fourth largest sediment discharge in the world, discharge about $1.08 \times 10^{9} \mathrm{t}$ and $4.78 \times 10^{8} \mathrm{t}$ sediments, respectively, to their adjacent seas annually [20]. Therefore, abundant sediments 
and nutrients were exported to the Bohai and the Yellow Sea, causing a high CSA concentration. However, in a previous study, most of the river discharged sediment was trapped in the estuary area and did not affect the outer sea directly [40,41], which was one of the reasons that the CSA near the Yellow and Yangtze river estuaries was higher than in the outer sea (Figure 4). Nevertheless, the river discharges and sediment carriages during the four seasons were different and their influences on CSA need to be studied further.

\subsection{Implications of Applications of CSA}

The CSA of the suspended particle is an important parameter that is relevant to the inherent optical properties of the suspended particle [15]. The distribution of CSA provides a new insight into the particle biogeochemical properties and the role of particles in the determination of water optical properties. Understanding the variability of the inherent optical properties is of great importance for radiative transfer studies in marine waters, studies coupling optics with ecosystems and biogeochemical models, in situ monitoring of suspended particle dynamics, as well as for ocean color remote sensing [10]. The CSA is closely related to the optical properties of the suspended particle, such as $b_{\mathrm{bp}}$, attenuation, and scattering coefficients $[7,11]$. With the appearance of flocs, the magnitude of observed $b_{\mathrm{bp}}$ may change slightly [9]. Compared with the TSM, the CSA was more responsible for the variations in the beam attenuation coefficient and $b_{\mathrm{bp}}$, with $R^{2}$ values of 0.910 and 0.906 , respectively [14]. The result was consistent with the study of Hatcher et al. [12], who observed the strong relationship between $b_{\mathrm{bp}}$ and the CSA in an experiment, and the study of Flory et al. [9], who observed $b_{\mathrm{bp}}$ increasing with the CSA of flocs, which implied that the CSA may be a better indicator to describe $b_{\mathrm{bp}}$ and the beam attenuation coefficient values and is more retrievable from ocean color measurements than TSM [7].

Usually, most remote sensing algorithms are empirical $[42,43]$ and are thus simple and rapid in data processing. However, such empirical models apply simple or multiple regressions between the property of interest and the ratios of irradiance reflectance or remote-sensing reflectance, and do not require a full understanding of the relationship between remote-sensing reflectance and the inherent optical properties [44], which may decrease the accuracy of these models and limit the applicability of these approaches when the bio-optical conditions depart from these representative data sets used to empirically derive the covariance relationships [45]. The semi-analytical model combines the empiricism and radiative transfer theory that can be applied to different water types, and the accuracy is often much better than those of the empirical algorithms [44]. Therefore, the understanding of CSA is essential for deepening the understanding of the inherent optical properties and improving the semi-analytical ocean color inversion algorithms.

Taking Equation (1) for example, $b_{\mathrm{bp}}$ equals the backscattering efficiency multiplied by the CSA of the particles per $\mathrm{m}^{3}$ of water, and there are equivalent efficiencies for absorption and scattering [46]. Therefore, inherent optical properties are linked with CSA by efficiency factors [10]. Recently, there is mounting evidence showing that the backscattering efficiency $\left(Q_{\text {bbe }}\right)$ is bound up with the particle composition [14,46]. For instance, Bowers [46] showed the relationship between the $Q_{\mathrm{bbe}}(\lambda)$ at $665 \mathrm{~nm}$ and the composition of particles (the particle mass ratio), which implied that the composition of the particles might be detected via $Q_{\text {bbe }}(665)$. Analogously, Wang et al. [14] discovered that all particles may be separated into two parts in the Bohai and the Yellow Sea, which were small mineral particles with low $Q_{b b e}$ and large and organic particles corresponding to high $Q_{b b e}$, respectively. The CSA can be derived from the satellite using the model established by Wang et al. [15], and based on the inherent optical properties algorithm [47], the backscattering coefficient can be calculated via satellite $R_{\mathrm{rs}}(\lambda)$. Hence, the $Q_{\text {bbe }}$ is available by calculating the ratio of backscattering coefficients and the CSA. The pattern of particles composition can be mapped based on the $Q_{\text {bbe }}$ derived from satellite, which is important for the optical properties of the type of particles found in coastal waters [46].

In addition, given the rapid and recent development of mainland, abundant sediments were exported to the Bohai and the Yellow Seas together with the accumulative effects of winds, currents and particle resuspension, leading to a low transparency for the water mass [24] and the increase in 
the extinction coefficient in the upper water [38]. Meanwhile, Wang [15] reported a strong correlation between CSA and transparency $\left(R^{2}=0.87\right)$ in the Bohai and the Yellow Sea and discovered that the distribution of CSA can potentially map transparency and photosynthetically active radiation, which would be of great importance to phytoplankton photosynthesis and water quality monitoring.

As reported in the previous study, the amount of suspended particles is commonly quantified by the TSM, and various algorithms have been developed to draw up TSM maps combined with remote sensing data $[43,48]$. Taking into account that the possibility of a photon interacting with particles depends on the CSA, the optical properties at the sea surface are more closely related to the CSA of suspended particles than to TSM [7,11]. This may imply that it is inappropriate to estimate TSM from $R_{\mathrm{rs}}(\lambda)$ because of an unstable relationship between TSM and $R_{\mathrm{rs}}(\lambda)$, and thereby introduce errors in TSM estimations. The relationship between CSA and TSM can be approximately expressed as follows [7,10]:

$$
T S M=\frac{2}{3} \rho D_{A} C S A
$$

where $\rho$ and $D_{\mathrm{A}}$ denote the overall density and the mean diameter of the suspended particles, respectively. This implies that the CSA distribution might act as an alternative approach for drawing up a TSM map. However, at present, estimating TSM from CSA also requires additional information on particle diameter and density [11], and this algorithm still needs to be further evaluated for whether this approach can improve estimations of TSM.

\section{Conclusions}

Field measurements from four seasons were used to study the seasonal and spatial CSA distributions in the Bohai Sea and the Yellow Sea. Obvious seasonal changes in the patterns of CSA were observed. In spring, despite the organic particles being highly concentrated due to the phytoplankton bloom, the gradually growing thermocline limited the bottom matters upwards, leading to a small CSA on the sea surface. The stratification in summer was strong enough to block the vertical mixing. As a result, the bottom sediments could not be carried to the sea surface so that the CSA on the surface was smallest, and the CSA maximum zone was in the subsurface due to the existence of SCML. In autumn, the strong wind and surface cooling induced vertical turbulent mixing and diffused the resuspended sediment, which may increase the CSA in the surface layer. Though the concentration of phytoplankton biomass in winter was small, the resuspension of sediments caused by the strongest vertical mixing became dominant, and hence the CSA was largest. In addition, the river runoff brought about a large amount of sediment discharge, which may have affected the CSA on the surface near the shore.

The mechanisms of the spatiotemporal CSA distribution were studied based on the in situ measured data, but acquiring the current velocity of each layer based on the field data was difficult. Thus, only the vertical mixing, phytoplankton, and river discharge influences on the CSA distribution were discussed. In addition, the episodic weather processes (for instance, the typhoons and storm tide) that can substantially influence the CSA over a short time need to be studied further.

Improved knowledge of CSA can deepen the understanding of inherent optical properties, and improve the remote sensing algorithms. Meanwhile, due to the strong relationship between the CSA and inherent optical properties, the CSA may be a superior indicator for describing the beam attenuation and backscattering coefficients values.

Author Contributions: Q.T. contributed to the data analyses and drafted the manuscript; S.W. assisted with developing the research design and results interpretation; Z.Q., D.S., and M.B. contributed to the interpretation of results and manuscript revision.

Funding: This research was funded by the National Key Research and Development Program of China (No. 2016YFC1400901 and 2016YFC1400904), National Natural Science Foundation of China (No. 41506200, 41876203 and 41576172), Provincial Natural Science Foundation of Jiangsu in China (No. BK2015914, BK20161532, BK20151526), Jiangsu Provincial Programs for Marine Science and Technology Innovation (HY2017-5), National 
Program on Global Change and Air-sea Interaction (No. GASI-03-03-01-01), Priority Academic Program Development of Jiangsu Higher Education Institutions (PAPD).

Acknowledgments: We deeply acknowledge anonymous reviewers for their constructive comments towards improving this manuscript.

Conflicts of Interest: The authors declare no conflict of interest.

\section{References}

1. Doxaran, D.; Froidefond, J.M.; Castaing, P.; Babin, M. Dynamics of the turbidity maximum zone in a macrotidal estuary (the Gironde, France): Observations from field and MODIS satellite data. Estuar. Coast. Shelf Sci. 2009, 81, 321-332. [CrossRef]

2. Soloviev, A.; Lukas, R. The Near-Surface Layer of the Ocean: Structure, Dynamics and Applications; Springer Science \& Business Media: Dordrecht, The Netherlands, 2013.

3. Kara, A.B.; Hurlburt, H.E.; Rochford, P.A.; O'Brien, J.J. The impact of water turbidity on interannual sea surface temperature simulations in a layered global ocean model. J. Phys. Oceanogr. 2004, 34, 345-359. [CrossRef]

4. Kirk, J.T. Effects of suspensoids (turbidity) on penetration of solar radiation in aquatic ecosystems. Hydrobiologia 1985, 125, 195-208. [CrossRef]

5. Binding, C.; Bowers, D.; Mitchelson-Jacob, E. Estimating suspended sediment concentrations from ocean colour measurements in moderately turbid waters; the impact of variable particle scattering properties. Remote Sens. Environ. 2005, 94, 373-383. [CrossRef]

6. Doron, M.; Babin, M.; Hembise, O.; Mangin, A.; Garnesson, P. Ocean transparency from space: Validation of algorithms estimating Secchi depth using MERIS, MODIS and SeaWiFS data. Remote Sens. Environ. 2011, 115, 2986-3001. [CrossRef]

7. Bowers, D.; Braithwaite, K. Evidence that satellites sense the cross-sectional area of suspended particles in shelf seas and estuaries better than their mass. Geo-Mar. Lett. 2012, 32, 165-171. [CrossRef]

8. Mobley, C.D. Light and Water: Radiative Transfer in Natural Waters; Academic Press: San Diego, CA, USA, 1994.

9. Flory, E.; Hill, P.; Milligan, T.; Grant, J. The relationship between floc area and backscatter during a spring phytoplankton bloom. Deep Sea Res. Part I: Oceanogr. Res. 2004, 51, 213-223. [CrossRef]

10. Neukermans, G.; Loisel, H.; Mériaux, X.; Astoreca, R.; McKee, D. In situ variability of mass-specific beam attenuation and backscattering of marine particles with respect to particle size, density, and composition. Limnol. Oceanogr. 2012, 57, 124-144. [CrossRef]

11. Mikkelsen, O.A. Variation in the projected surface area of suspended particles: Implications for remote sensing assessment of TSM. Remote Sens. Environ. 2002, 79, 23-29. [CrossRef]

12. Hatcher, A.; Hill, P.; Grant, J. Optical backscatter of marine flocs. J. Sea Res. 2001, 46, 1-12. [CrossRef]

13. Brown, C.A.; Huot, Y.; Werdell, P.J.; Gentili, B.; Claustre, H. The origin and global distribution of second order variability in satellite ocean color and its potential applications to algorithm development. Remote Sens. Environ. 2008, 112, 4186-4203. [CrossRef]

14. Wang, S.; Qiu, Z.; Sun, D.; Shen, X.; Zhang, H. Light beam attenuation and backscattering properties of particles in the Bohai Sea and Yellow Sea with relation to biogeochemical properties. J. Geophys. Res. Oceans 2016, 121, 3955-3969. [CrossRef]

15. Wang, S.; Huan, Y.; Qiu, Z.; Sun, D.; Zhang, H.; Zheng, L.; Xiao, C. Remote sensing of particle cross-sectional area in the Bohai Sea and Yellow Sea: algorithm development and application implications. Remote Sens. 2016, 8, 841. [CrossRef]

16. Milligan, T. In situ particle (floc) size measurements with the benthos 373 plankton silhouette camera. J. Sea Res. 1996, 36, 93-100. [CrossRef]

17. Agrawal, Y.; Pottsmith, H. Instruments for particle size and settling velocity observations in sediment transport. Mar. Geol. 2000, 168, 89-114. [CrossRef]

18. Sun, D.; Qiu, Z.; Hu, C.; Wang, S.; Wang, L.; Zheng, L.; Peng, T.; He, Y. A hybrid method to estimate suspended particle sizes from satellite measurements over Bohai Sea and Yellow Sea. J. Geophys. Res. Oceans 2016, 121, 6742-6761. [CrossRef]

19. Zhang, S.; Wang, Q.; Lü, Y.; Cui, H.; Yuan, Y. Observation of the seasonal evolution of the Yellow Sea Cold Water Mass in 1996-1998. Cont. Shelf Res. 2008, 28, 442-457. [CrossRef] 
20. Bian, C.; Jiang, W.; Quan, Q.; Wang, T.; Greatbatch, R.J.; Li, W. Distributions of suspended sediment concentration in the Yellow Sea and the East China Sea based on field surveys during the four seasons of 2011. J. Mar. Syst. 2013, 121, 24-35. [CrossRef]

21. Morel, A.; Prieur, L. Analysis of variations in ocean color 1. Limnol. Oceanogr. 1977, 22, 709-722. [CrossRef]

22. Wei, H.; Sun, J.; Moll, A.; Zhao, L. Phytoplankton dynamics in the Bohai Sea-observations and modelling. J. Mar. Syst. 2004, 44, 233-251. [CrossRef]

23. Fan, H.; Huang, H. Response of coastal marine eco-environment to river fluxes into the sea: A case study of the Huanghe (Yellow) River mouth and adjacent waters. Mar. Environ. Res. 2008, 65, 378-387. [CrossRef] [PubMed]

24. Zhang, M.; Tang, J.; Song, Q.; Dong, Q. Backscattering ratio variation and its implications for studying particle composition: A case study in Yellow and East China seas. J. Geophys. Res. Oceans 2010, 115, C12. [CrossRef]

25. Agrawal, Y.; Traykovski, P. Particles in the bottom boundary layer: Concentration and size dynamics through events. J. Geophys. Res. Oceans 2001, 106, 9533-9542. [CrossRef]

26. Felix, D.; Albayrak, I.; Boes, R.M. Laboratory investigation on measuring suspended sediment by portable laser diffractometer (LISST) focusing on particle shape. Geomar. Lett. 2013, 33, 485-498. [CrossRef]

27. Traykovski, P.; Latter, R.J.; Irish, J.D. A laboratory evaluation of the laser in situ scattering and transmissometery instrument using natural sediments. Mar. Geol. 1999, 159, 355-367. [CrossRef]

28. Agrawal, Y.; Whitmire, A.; Mikkelsen, O.A.; Pottsmith, H. Light scattering by random shaped particles and consequences on measuring suspended sediments by laser diffraction. J. Geophys. Res. Oceans 2008, 113, C4. [CrossRef]

29. Reynolds, R.; Stramski, D.; Wright, V.; Woźniak, S. Measurements and characterization of particle size distributions in coastal waters. J. Geophys. Res. Oceans 2010, 115, C8. [CrossRef]

30. Sievers, H.A.; Nowlin, W.D., Jr. The stratification and water masses at Drake Passage. J. Geophys. Res. Oceans 1984, 89, 10489-10514. [CrossRef]

31. Helber, R.W.; Kara, A.B.; Richman, J.G.; Carnes, M.R.; Barron, C.N.; Hurlburt, H.E.; Boyer, T. Temperature versus salinity gradients below the ocean mixed layer. J. Geophys. Res. Oceans 2012, 117, C5. [CrossRef]

32. Su, J.; Yuan, Y. China Offshore Hydrologica; China Ocean Press: Beijing, China, 2005.

33. Sun, X. China Offing Sea; China Ocean Press: Beijing, Chnia, 2006.

34. Bogucki, D.; Dickey, T.; Redekopp, L.G. Sediment resuspension and mixing by resonantly generated internal solitary waves. J. Phys. Oceanogr. 1997, 27, 1181-1196. [CrossRef]

35. Vangriesheim, A.; Springer, B.; Crassous, P. Temporal variability of near-bottom particle resuspension and dynamics at the Porcupine Abyssal Plain, Northeast Atlantic. Prog. Oceanogr. 2001, 50, 123-145. [CrossRef]

36. Ladd, C.; Thompson, L.A. Decadal variability of North Pacific central mode water. J. Phys. Oceanogr. 2002, 32, 2870-2881. [CrossRef]

37. Luo, Y.; Liu, Q.; Rothstein, L.M. Increase of South Pacific eastern subtropical mode water under global warming. Geophys. Res. Lett. 2011, 38, 1. [CrossRef]

38. Zhang, H.; Qiu, Z.; Sun, D.; Wang, S.; He, Y. Seasonal and interannual variability of satellite-derived chlorophyll-a (2000-2012) in the bohai sea, china. Remote Sens. 2017, 9, 582. [CrossRef]

39. Gong, X.; Shi, J.; Gao, H. Modeling seasonal variations of subsurface chlorophyll maximum in South China Sea. J. Ocean Univ. China 2014, 13, 561-571. [CrossRef]

40. Meade, R.H. River-sediment inputs to major deltas. In Sea-Level Rise and Coastal Subsidence; Kluwer: Dordrecht, The Netherlands, 1996; pp. 63-85.

41. Liu, J.; Xu, K.; Li, A.e.a.; Milliman, J.; Velozzi, D.; Xiao, S.; Yang, Z. Flux and fate of Yangtze River sediment delivered to the East China Sea. Geomorphology 2007, 85, 208-224. [CrossRef]

42. Gordon, H.R.; Clark, D.K.; Brown, J.W.; Brown, O.B.; Evans, R.H.; Broenkow, W.W. Phytoplankton pigment concentrations in the Middle Atlantic Bight: comparison of ship determinations and CZCS estimates. Appl. Opt. 1983, 22, 20-36. [CrossRef] [PubMed]

43. Qiu, Z. A simple optical model to estimate suspended particulate matter in Yellow River Estuary. Opt. Express 2013, 21, 27891-27904. [CrossRef]

44. Qiu, Z.; Su, Y.; Yang, A.; Wang, L.; Mao, Z.; Zhou, B.; Chen, S. An approach for estimating absorption and backscattering coefficients from MERIS in the Bohai Sea. Int. J. Remote Sens. 2014, 35, 8169-8187. [CrossRef] 
45. Smyth, T.J.; Moore, G.F.; Hirata, T.; Aiken, J. Semianalytical model for the derivation of ocean color inherent optical properties: description, implementation, and performance assessment. Appl. Opt. 2006, 45, 8116-8131. [CrossRef]

46. Bowers, D.; Hill, P.; Braithwaite, K. The effect of particulate organic content on the remote sensing of marine suspended sediments. Remote Sens. Environ. 2014, 144, 172-178. [CrossRef]

47. Lee, Z.; Carder, K.L.; Arnone, R.A. Deriving inherent optical properties from water color: a multiband quasi-analytical algorithm for optically deep waters. Appl. Opt. 2002, 41, 5755-5772. [CrossRef] [PubMed]

48. Miller, R.L.; McKee, B.A. Using MODIS Terra $250 \mathrm{~m}$ imagery to map concentrations of total suspended matter in coastal waters. Remote Sens. Environ. 2004, 93, 259-266. [CrossRef]

(C) 2019 by the authors. Licensee MDPI, Basel, Switzerland. This article is an open access article distributed under the terms and conditions of the Creative Commons Attribution (CC BY) license (http://creativecommons.org/licenses/by/4.0/). 